\title{
Cardiopulmonary exercise pattern in patients with persistent dyspnoea after recovery from COVID-19
}

\author{
Arno Mohr, ${ }^{1}$ Laura Dannerbeck, ${ }^{1}$ Tobias J. Lange, ${ }^{2}$ Michael Pfeifer, ${ }^{1,2}$ Stefan Blaas, ${ }^{1}$ Bernd Salzberger, ${ }^{3}$ \\ Florian Hitzenbichler, ${ }^{3}$ Myriam Koch ${ }^{2}$ \\ ${ }^{1}$ Center for Pneumology, Donaustauf Hospital, Donaustauf \\ ${ }^{2}$ Department of Internal Medicine 2, University Medical Center, Regensburg \\ ${ }^{3}$ Department of Infection Control and Infectious Diseases, University Medical Center Regensburg, Germany
}

\begin{abstract}
Cause and mechanisms of persistent dyspnoea after recovery from COVID-19 are not well described. The objective is to describe causal factors for persistent dyspnoea in patients after COVID-19. We examined patients reporting dyspnoea after recovery from COVID-19 by cardiopulmonary exercise testing. After exclusion of patients with pre-existing lung diseases, ten patients (mean age 50 \pm 13.1 years) were retrospectively analysed between May $14^{\text {th }}$ and September $15^{\text {th }}, 2020$. On chest computed tomography, five patients showed residual ground glass opacities, and one patient showed streaky residua. A slight reduction of the mean diffusion capacity of the lung for carbon monoxide was noted in the cohort. Mean peak oxygen uptake was reduced with $1512 \pm 232 \mathrm{ml} / \mathrm{min}(72.7 \%$ predicted), while mean peak work rate was preserved with $131 \pm 29 \mathrm{~W}$ (92.4\% predicted). Mean alveolar-arterial oxygen gradient $\left(\mathrm{AaDO}_{2}\right)$ at peak exercise was $25.6 \pm 11.8 \mathrm{mmHg}$. Mean value of lactate post exercise was $5.6 \pm 1.8 \mathrm{mmol} / \mathrm{l}$. A gap between peak work rate in $(92.4 \%$ predicted) to peak oxygen uptake ( $72.3 \%$ pred.) was detected in our study cohort. Mean value of lactate post exercise was high in our study population and even higher (n.s.) compared to the subgroup of patients with reduced peak oxygen uptake and other obvious reason for limitation. Both observations support the hypothesis of anaerobic metabolism. The main reason for dyspnoea may therefore be muscular.
\end{abstract}

Key words: CPET; COVID-19; postdischarge dyspnoea; post-COVID-19 syndrome.

Correspondence: Dr. Myriam Koch, Klinik und Poliklinik für Innere Medizin II, Universitätsklinikum Regensburg, Franz-Josef-Strauß Allee 11, D-93053 Regensburg, Germany. Tel. +49.941/944-0. E-mail: myriam.koch@ukr.de

Contributions: All authors made a substantive intellectual contribution, read and approved the final version of the manuscript and agreed to be accountable for all aspects of the manuscript.

Conflict of interest: LD, MP and MK have nothing to disclose; AM reports grants from Gilead Sciences, outside the submitted work; TJL reports personal fees from Actelion, personal fees from Janssen-Cilag, personal fees from BMS, personal fees from MSD, personal fees from Pfizer, personal fees from GSK, personal fees from Acceleron Pharma, outside the submitted work; SB reports personal fees and non-financial support from Roche, personal fees and non-financial support from Boehringer Ingelheim, non-financial support from Teva, personal fees and non-financial support from Bayer, non-financial support from Gilead, personal fees and non-financial support from Novartis, personal fees from Merck Serono, non-financial support from Lucane Pharma, non-financial support from Actelion, non-financial support from CSL Behring, non-financial support from Vertex, outside the submitted work; BS reports personal fees from Roche Ag, personal fees from Sanofi, personal fees from Falk Foundation, outside the submitted work; FH reports grants from Gilead Sciences, personal fees from MSD, outside the submitted work.

Funding: The authors received no specific funding for this work.

Availability of data and materials: The dataset analysed during the current study is available from the corresponding author upon reasonable request.

Ethics approval and consent to participate: The retrospective study was approved by the local ethics committee (No. 201773-104) at the University of Regensburg.

Consent for publication: Not applicable. 


\section{Introduction}

COVID-19 has led to more than 2 millions deaths in less than 12 months [1]. Mankind is challenged by this new disease, which in many aspects and characteristics is different to other respiratory viral infections [2-4]. Manifestations range from asymptomatic infection to severe ARDS. Some survivors suffer from symptoms, attributable to ICU care and some show persisting symptoms which are still unclear [5]. Some patients do not report dyspnoea despite hypoxemia in severe COVID-19 [2,6]. Interestingly after recovery from acute infection with SARS-CoV2 dyspnoea and fatigue are the most frequent symptoms [7-10]. However, the cause and pathophysiologic mechanisms of persistent dyspnoea after recovery from COVID-19 are not well described. In this study we sought to analyse our cohort of post COVID-19 patients with persistent dyspnoea using a thorough clinical workup including cardiopulmonary exercise testing (CPET).

\section{Methods}

\section{Study population, study design and data collection}

The study was conducted at the Centre of Pneumology in Donaustauf, Germany. The hospital is a quaternary care provider for pneumology, where patients from the eastern region of Bavaria are seen for specialized care.

All available medical reports from patients, that presented to the outpatient's clinic or on Non-ICU ward with persistent symptoms after recovery from COVID-19 (post-COVID-19) between May $14^{\text {th }}$ and September $15^{\text {th }} 2020$ were retrospectively analysed.

\section{Statistics}

Summary statistics of continuous variables are presented as mean \pm standard deviation. Data were analysed using Microsoft Excel (version 2016, Redmond, USA) and IBM SPSS (version 24.0, IBM, Armonk, USA).

\section{Patients}

The following eligibility criteria were applied: 18 years of age or older, post COVID-19, still symptomatic with dyspnoea. Patients were excluded from the study if any of the above criteria was not fulfilled or if no CPET was performed or any other reason for dyspnoea became evident. Abnormal spirometry was not a strict exclusion criterion except reflecting an underlying lung disease judged responsible for patient's dyspnoea.

\section{Examinations}

Patients received a comprehensive assessment of dyspnoea including blood gas analysis, lung function test, 6-min walk test, echocardiography, computed chest tomography (CT) scan, thoracic sonography, and CPET. Due to the retrospective nature of our study, examinations mentioned (except CPET) were not performed in the entire patient population.

\section{Results}

\section{Baseline characteristics}

In the time period 42 patients post COVID-19 were seen at our hospital, 31 patients were excluded because no CPET was performed. Ten patients met the eligibility criteria. Mean age of these patients was $50 \pm 13.1$ years and four patients were female. In the acute phase of COVID-19 six patients had been hospitalized, five patients needed oxygen, two patients needed high-flow oxygen therapy, and in two patients invasive ventilation was necessary. Mean hospital stay was $23.4 \pm 22.0$ days; mean time to presentation to our outpatient's clinic after hospital discharge were 115 days. None of the participants had a history of lung disease, congestive heart failure, diabetes mellitus or malignancy. There were five patients with known "arterial hypertension", one patient had an ACE inhibitor in his regular medication.

Ejection fraction in transthoracic echocardiography was normal in all patients. One patient showed a slightly dilated right ventricle with a mild tricuspid valve insufficiency (PAP elevation 60 $\mathrm{mmHg}$ over central venous pressure). No other patient showed signs of an acute right heart strain. Thorax sonography was performed in two patients showing normal diaphragm function. Chest CT scan was performed in all patients. Five patients showed ground glass opacities and one patient showed streaky residua. Pulmonary embolism, as possible reason for the dyspnoea, was excluded by CT scan in nine patients (one patient had a CT scan without contrast agent but a low likelihood in Wells-Score and negative d-dimer testing)

No participant had obstructive lung disease. A nominal reduction of the diffusion capacity of the lung for carbon monoxide $\left(\mathrm{DL}_{\mathrm{CO}}\right)$ of $73 \%$ was recognized in the cohort.

\section{Cardiopulmonary exercise testing}

Peak oxygen uptake (Peak- $\mathrm{VO}_{2}$ ) was measured by CPET with $1512 \pm 232 \mathrm{ml} / \mathrm{min}(72.7 \%$ predicted) at a mean peak work rate of $131 \pm 29 \mathrm{~W}$ (92.4\% pred.). Mean alveolar-arterial oxygen gradient $\left(\mathrm{AaDO}_{2}\right)$ at peak exercise was $25.6 \pm 11.8 \mathrm{mmHg}$, mean peak ventilation was $64.7 \mathrm{l} / \mathrm{min}$ and mean breathing reserve (BR) was $35.1 \pm 19.0 \%$. Mean heart rate during exercise was $133 \pm 19 / \mathrm{min}$ (78.1 \pm 7.3 pred.), oxygen pulse $11.9 \pm 2.6$ (96.0 $\pm 15.5 \%$ pred.). Mean $\mathrm{EQCO}_{2}$ and mean $\mathrm{EQO}_{2}$ at VT1 were measured with $35.4 \pm 6.5$ and $28.7 \pm 10.4$. Mean value of lactate post exercise was $5.6 \pm 1.8 \mathrm{mmol} / \mathrm{l}$. A detailed description of all patients is presented in Table 1.

In detail CPET detected a nearly normal performance $\left(\mathrm{VO}_{2} \max \geq 85 \%\right)$ in two of the patients (No 3 and No 8 ), eight patients (beside No 1 and No 10) had elevated (>30) $\mathrm{EQCO}_{2}$ values at VT1. Limitation was cardiac in one patient (No 5) and ventilatory (BR <30\%) in two patients. $\mathrm{AaDO}_{2}$ was elevated in three patients (No 3, No 4 and No 8). Dyspnoea during CPET was quantified via RPE scale (range 3-9).

\section{Discussion}

To our knowledge, this is the first study examining patients with persistent dyspnoea after COVID-19. Persistent dyspnoea in patients, who recovered from acute COVID-19 infection has been described [7-9].

The gap between reached peak work rate $(92.4 \%$ predicted) to peak oxygen uptake $(72.3 \%$ pred.) in our study population can most likely be explained by an early switch to anaerobic metabolism. This would explain why mean value of lactate post exercise was high in our study population and even higher (n.s.) compared to the subgroup of patients with reduced peak oxygen uptake and other obvious reason for limitation.

In two patients the limitation was ventilatory. Critical-illnesspolyneuropathy may have contributed in patient Nos 7 and 8 . $\mathrm{AaDO}_{2}$ was elevated in three patients (No 3, No 4 and No 8), all of them had ground-glass opacity or streaky residua on the CT-scan. Finally, even with the use of CPET, dyspnoea could not be 


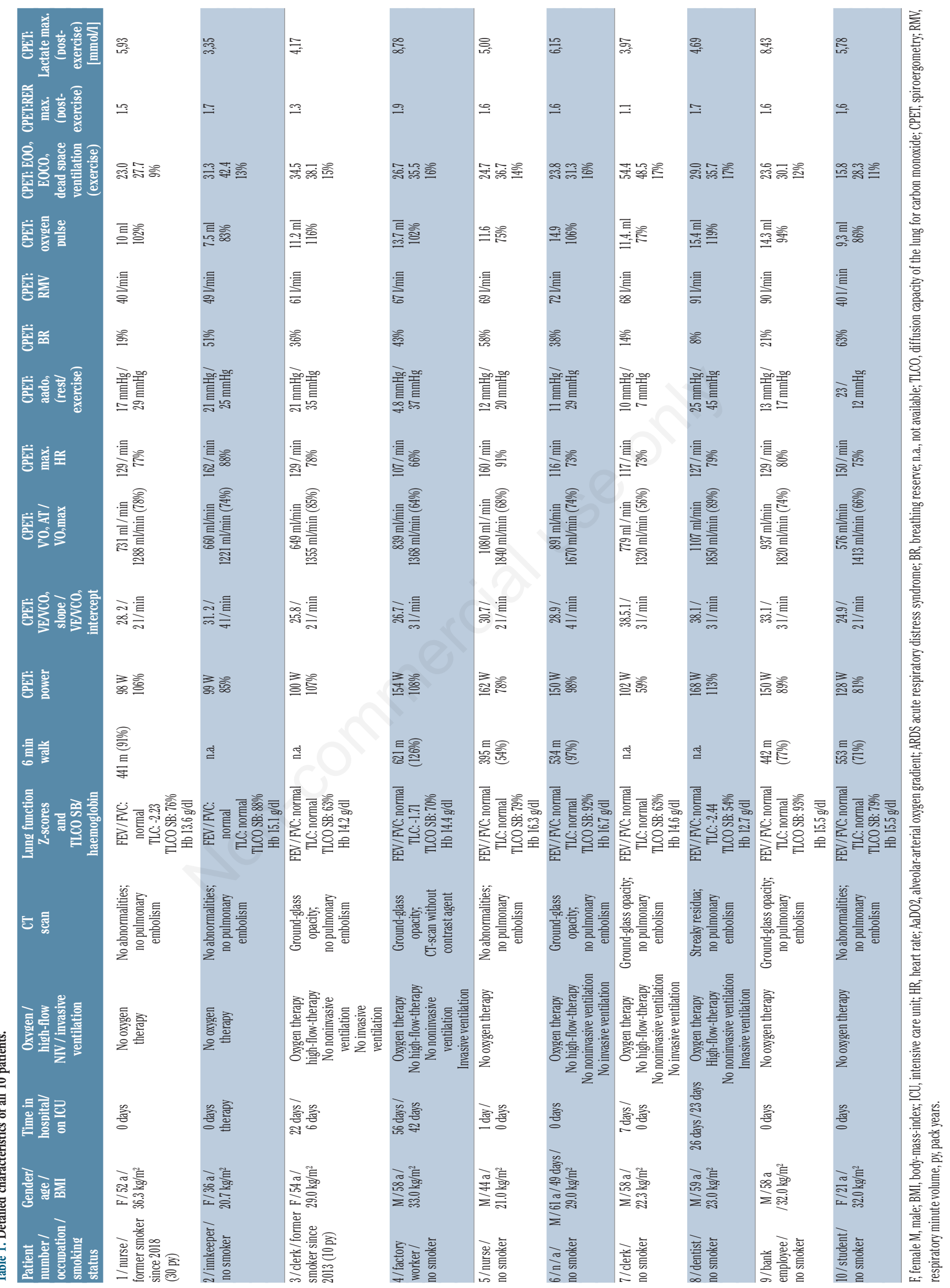


explained by cardiac, pulmonary or ventilatory limitation in all patients. Muscular deficiency and thus metabolic limitation might have contributed to dyspnoea in most patients. As in other viral diseases in adults (e.g., EBV) and in acute respiratory distress syndrome (ARDS), complete clinical recovery might be prolonged in COVID-19 [7,11-13]. However, the reason for muscular deficiency itself is unclear. It could either be due to atrophy as a consequence of insufficient physical load or critical-illness-polyneuropathy or direct damage of muscle or central nervous system by SARS-Cov2 [14].

\section{Limitations}

Our study has many limitations. First of all, it is retrospective and the number of patients being included is very small. Second, it is a single centre study; on the other hand, this is the first study at all analysing persistent dyspnoea in patients with COVID-19 via CPET.

\section{Conclusion}

Despite the use of CPET, dyspnoea could not be explained by cardiac, pulmonary or ventilatory limitation in all patients. A gap between peak work rate in $(92.4 \%$ predicted) to peak oxygen uptake (72. \% pred.) was detected in our study cohort. Mean value of lactate post exercise was high in our study population and even higher (n.s.) compared to the subgroup of patients with reduced peak oxygen uptake and other obvious reason for limitation. Both observations support the hypothesis of anaerobic metabolism. Muscular deficiency and thus metabolic limitation might contribute to dyspnoea in most patients. Further prospective studies with more participants are needed to evaluate the aetiology of dyspnoea post COVID-19.

\section{References}

1. WHO. Coronavirus Disease (COVID-19) Dashboard 2020 [updated 09.09.2020]. Available from: https://covid19.who.int/

2. Guan WJ, Ni ZY, Hu Y, Liang WH, Ou CQ, He JX, et al. Clinical characteristics of coronavirus disease 2019 in China.
N Engl J Med 2020;382:1708-20.

3. Li Q, Guan X, Wu P, Wang X, Zhou L, Tong Y, et al. Early transmission dynamics in Wuhan, China, of novel coronavirusinfected pneumonia. N Engl J Med 2020;382:1199-207.

4. Wölfel R, Corman VM, Guggemos W, Seilmaier M, Zange S, Müller MA, et al. Virological assessment of hospitalized patients with COVID-2019. Nature 2020;581:465-9.

5. Kaye R, Chang CWD, Kazahaya K, Brereton J, Denneny JC, 3rd. COVID-19 anosmia reporting tool: Initial findings. Otolaryngology--head and neck surgery : official journal of American Academy of Otolaryngol Head Neck Surg 2020;163:132-4.

6. Huang C, Wang Y, Li X, Ren L, Zhao J, Hu Y, et al. Clinical features of patients infected with 2019 novel coronavirus in Wuhan, China. Lancet 2020;395:497-506.

7. Halpin SJ, McIvor C, Whyatt G, Adams A, Harvey O, McLean $\mathrm{L}$, et al. Postdischarge symptoms and rehabilitation needs in survivors of COVID-19 infection: A cross-sectional evaluation. J Med Virol 2020;93:1013-22.

8. Carfì A, Bernabei R, Landi F. Persistent symptoms in patients after acute COVID-19. JAMA 2020;324:603-5.

9. Wang X, Xu H, Jiang H, Wang L, Lu C, Wei X, et al. The clinical features and outcomes of discharged coronavirus disease 2019 patients: A prospective cohort study. QJM 2020;113:65765.

10. Garrigues E, Janvier P, Kherabi Y, Bot AL, Hamon A, Gouze $\mathrm{H}$, et al. Post-discharge persistent symptoms and health-related quality of life after hospitalization for COVID-19. J Infect 2020;81:e4-6.

11. Dunmire SK, Verghese PS, Balfour HH, Jr. Primary EpsteinBarr virus infection. J Clin Virol 2018;102:84-92.

12. Balfour HH Jr, Dunmire SK, Hogquist KA. Infectious mononucleosis. Clin Transl Immunology 2015;4:e33.

13. Brandstetter S, Dodoo-Schittko F, Brandl M, Blecha S, Bein T, Apfelbacher C. Ambulatory and stationary healthcare use in survivors of ARDS during the first year after discharge from ICU: findings from the DACAPO cohort. Ann Intensive Care 2019;9:70.

14. Orsucci D, Ienco EC, Nocita G, Napolitano A, Vista M. Neurological features of COVID-19 and their treatment: a review. Drugs Contex 2020;9:2020-5-1. 